\title{
Unsymmetrical Schiff Base Functionalized as Monobasic Tridentate Ligand on Complexation with Some Transition Metal Ions
}

\author{
BIBHESH K. SINGH ${ }^{1 *}$, NARENDAR BHOJAK ${ }^{2}$, and ANANT PRAKASH ${ }^{1}$ \\ ${ }^{1}$ Inorganic \& Bioinorganic Research Lab \\ Department of Chemistry, Govt. Post Graduate College \\ Ranikhet-263645 (Uttarakhand) India \\ ${ }^{2}$ Department of Chemistry, Govt Dunger College \\ MGS University, Bikaner (Rajasthan) India \\ bibheshksingh@yahoo.co.in
}

Received 12 July 2011; Accepted 5 September 2011

\begin{abstract}
Cu}(\mathrm{II}), \mathrm{Co}(\mathrm{II}), \mathrm{Ni}(\mathrm{II})$ and $\mathrm{Mn}$ (II) complexes of Schiff base derived from 2-aminophenol and pyrrole-2- carbaldehyde have been prepared. The complexes are formed by coordination of $\mathrm{N}$ and $\mathrm{O}$ atoms of the ligand. Their structures were characterized by physico-chemical and spectroscopic methods. Molecular structure of the complexes has been optimized by MM2 calculations and suggests a tetrahedral/ square planar geometry. The bio-efficacy of the ligand and their complexes has been examined against the growth of bacteria in vitro to evaluate their anti-microbial potential.
\end{abstract}

Keywords: Bioactivity, Electrochemical studies, Molecular modeling, Schiff base, Spectra, Transition metal complexes.

\section{Introduction}

Presently, there is a growing interest in the coordination chemistry of structurally modified bio-ligands. Transition metal complexes with potential biological activity are the focus of extensive investigations. Schiff base complexes are used as catalyst in some chemical processes, as biological models for understanding the structures of bio-molecules and to emulate the activity of proteins ${ }_{1}$. Several azomethines were reported to possess remarkable antimicrobial $^{2}$, anticancer ${ }^{3}$ and diuretic activities ${ }^{4}$. Schiff bases and their complexes were recently found to have significant antitumor and biological activity ${ }^{5}$. During the last decade, the coordination chemistry of Schiff bases derived from heterocyclic carbaldehyde has received much attention ${ }^{6}$. Recently, the stability of Schiff bases in the presence of Sm(II) reagent, is determined by the introduction of a pyrrole ring, able to coordinate to $\mathrm{Sm}$ (II) ion has been studied $^{7}$. With the increasing incidence of deep mycosis, there has been increasing emphasis on the screening of new and more effective antimicrobial drugs with low toxicity. In order the need to find cheap and effective antibacterial agents, we synthesized new complexes of 
transition metals with newly synthesized Schiff base ligand. Furthermore, it was also intended to screen these complexes for antimicrobial activities against Escherichia coli(Gram- negative) and Staphylococcus aureus(Gram- positive) bacteria, ${ }^{8,9}$. Here we report the syntheses, characterization and biological activities of transition metal complexes of tridentate Schiff base ligand.

\section{Experimental}

All the chemicals used were of analytical grade and used as received. The metal salts used were $\mathrm{Cu}(\mathrm{OAc})_{2} \cdot 2 \mathrm{H}_{2} \mathrm{O}, \mathrm{Co}\left(\mathrm{NO}_{3}\right)_{2} \cdot 6 \mathrm{H}_{2} \mathrm{O}, \mathrm{Ni}(\mathrm{OAc})_{2} \cdot 4 \mathrm{H}_{2} \mathrm{O}, \mathrm{MnCl}_{2} \cdot 4 \mathrm{H}_{2} \mathrm{O}$. The elemental analysis $(\mathrm{C}, \mathrm{H}$, and $\mathrm{N})$ of the complexes were performed using Elementar vario EL III model. Metal contents were estimated on an AA-640-13 Shimadzu flame atomic absorption spectrophotometer in solutions prepared by decomposing the complex in hot concentrated $\mathrm{HNO}_{3}$. The IR spectra were recorded on Perkin-Elmer FTIR spectrophotometer in $\mathrm{KBr}$ and polyethylene pellets in the region $4000-400 \mathrm{~cm}^{-1}$ and $400-100 \mathrm{~cm}^{-1}$, respectively. The UV-visible spectra of $0.005 \mathrm{M}$ solution were recorded in DMSO on Beckman DU-64 spectrophotometer with quartz cells of $1 \mathrm{~cm}$ path length and mass spectra (TOF-MS) were recorded on Waters $\mathrm{KC}-455$ model with $\mathrm{ES}^{+}$mode in DMSO. ${ }^{1} \mathrm{H}$ NMR spectra were recorded in DMSO- $\mathrm{d}_{6}$ solvent on a Bruker Advance 400 instrument. X-band EPR spectra was recorded on a Varian E-112 spectrometer with a variable temperature liquid nitrogen cryostat (The error in $\mathrm{g}$ value is \pm 0.001 ) and $\mathrm{g}$ factors were quoted relative to the standard marker TCNE $(\mathrm{g}=2.00277)$. Cyclic voltammetric measurements were carried out on a BAS $\mathrm{CV} 50 \mathrm{~W}$ electrochemical analyzing system(accuracy $\pm 1.0 \mathrm{mV}$ ) at room temperature in threeelectrode cell using nitrogen purged DMSO solution containing $0.1 \mathrm{M}$ TBAP and $10^{-3} \mathrm{M}$ of the complex. A Pt wire is used as a working electrode and $\mathrm{Ag} / \mathrm{AgCl}$ as a reference electrode. Magnetic susceptibility measurements were carried out at room temperature in powder form on a vibrating sample magnetometer PAR 155 with 5000G-field strength, using $\mathrm{Co}\left[\mathrm{Hg}(\mathrm{SCN})_{4}\right]$ as the calibrant(magnetic susceptibility $\approx 1.644 \times 10^{-5} \mathrm{~cm}^{3} \mathrm{~g}^{-1}$ ). Rigaku model 8150 thermoanalyser was used for simultaneous recording of TG-DTA curves at a heating rate of $10 \mathrm{~min}^{-1}$. For TG, the instrument was calibrated using calcium oxalate, while for DTA, calibration was done using indium metal, both of which were supplied along with the instrument. A flat bed type aluminum crucible was used with $\alpha$ - alumina ( $99 \%$ pure) as the reference material for DTA.

\section{Synthesis of metal complexes}

The newly synthesized ligand 2-[(1H-pyrrole-2-ylmethylene)amino]phenol[10] (Figure 1) $(5 \mathrm{mmol})$ in $\mathrm{EtOH}(20 \mathrm{~mL})$ was added dropwise to a solution containing metal salts $(5 \mathrm{mmol})$ in EtOH $(20 \mathrm{~mL})$. The mixture was stirred for $4 \mathrm{~h}$ at $60{ }^{\circ} \mathrm{C}$. The precipitate were filtered, washed with cold alcohol and dried under vacuum over silica gel. The yield and melting point of each product was determined.<smiles>OC1C2C=CC(O)(CC2)C1/N=C/c1ccc[nH]1</smiles>

Figure 1. Structure of the Ligand.

\section{Copper(II)- 2-[(1H-pyrrole-2-ylmethylene)amino]phenol complex [Complex I]}

Light Blue crystal; Yield: $82 \%$; Anal. Calcd. for $\mathrm{C}_{13} \mathrm{H}_{16} \mathrm{~N}_{2} \mathrm{O}_{5} \mathrm{Cu}$ requires (\%): C, 45.40; $\mathrm{H}$, 4.65; N, 8.15; Cu, 18.49. Found: C, 45.41; H, 4.62; N, 8.14, Cu, 18.48 [M.P $\left({ }^{\circ} \mathrm{C}\right): 185$ ]; FTIR( $\left.\mathrm{KBr}, \mathrm{cm}^{-1}\right): v(\mathrm{C}=\mathrm{N}): 1625(\mathrm{~s}) ; \mathrm{v}(\mathrm{M}-\mathrm{N}): 490(\mathrm{~m}) ; \mathrm{v}(\mathrm{M}-\mathrm{O}): 580(\mathrm{~m}) ;\left[\mathrm{v}_{\mathrm{as}}\left(\mathrm{CO}_{2}\right): 1620(\mathrm{~m})\right.$; 
$\left.v_{\mathrm{s}}\left(\mathrm{CO}_{2}\right): 1418(\mathrm{~s})\right]$; TOF-MS(m/z values): $345\left(45 \%, \mathrm{M}^{\dagger}\right), 309\left(12 \%,\left[\mathrm{M}(\mathrm{L})(\mathrm{X})^{\dagger \dagger}\right), 186\left(100 \%, \mathrm{LH}^{]^{+\dagger}}\right)\right.$, $146\left(67 \%, \mathrm{C}_{9} \mathrm{H}_{8} \mathrm{NO}^{1+}\right) ; \mu_{\text {eff }}(\mathrm{BM}): 1.75$;

Cobalt(II)- 2-[(1H-pyrrole-2-ylmethylene)amino]phenol complex [Complex II]

Brown crystal; Yield: 85\%; Anal. Calcd. for $\mathrm{C}_{11} \mathrm{H}_{13} \mathrm{~N}_{3} \mathrm{O}_{6} \mathrm{Co}$ requires (\%): C, 38.60; $\mathrm{H}$, $3.80 ; \mathrm{N}, 12.28 ; \mathrm{Co}, 17.23$. Found: C, 38.57; H, 3.81; N, 12.27, Co, 17.22 [M.P $\left({ }^{\circ} \mathrm{C}\right)$ : 200]; FTIR( KBr, cm $\left.{ }^{-1}\right): v(\mathrm{C}=\mathrm{N}): 1620(\mathrm{~s}) ; \mathrm{v}(\mathrm{M}-\mathrm{N}): 532(\mathrm{w}) ; \mathrm{v}(\mathrm{M}-\mathrm{O}): 613(\mathrm{~m}) ;\left[\mathrm{v} \mathrm{NO}_{3}{ }^{-}\right)$: $\left.1270\left(v_{1}\right), \quad 1095\left(v_{2}\right), 730\left(v_{3}\right), \quad 1383\left(v_{4}\right), 965\left(v_{5}\right), 1035\left(v_{6}\right)\right] ; \quad$ TOF-MS(m/z values): 343 $\left(52 \%, \mathrm{M}^{+}\right), 307\left(19 \%,\left[\mathrm{M}(\mathrm{L})(\mathrm{X})^{]^{+}}\right), \quad 185\left(91 \%, \mathrm{LH}^{]^{+}}\right), \quad 146\left(74 \%, \mathrm{C}_{9} \mathrm{H}_{8} \mathrm{NO}^{]^{+}}\right) ; \mu_{\mathrm{eff}}(\mathrm{BM})\right.$ : 4.22;

Nickel(II)- 2-[(1H-pyrrole-2-ylmethylene)amino]phenol complex [Complex III]

Dark Brown crystal; Yield: $82 \%$; Anal. Calcd. for $\mathrm{C}_{13} \mathrm{H}_{16} \mathrm{~N}_{2} \mathrm{O}_{5} \mathrm{Ni}$ requires (\%): C, 46.05; $\mathrm{H}$, 4.72; N, 8.26; Ni, 17.33. Found: C, 46.05; H, 4.71; N, 8.25, Ni, 17.32 [M.P( $\left.\left({ }^{\circ} \mathrm{C}\right): 175\right]$ ] FTIR $\left(\mathrm{KBr}, \quad \mathrm{cm}^{-1}\right): \quad v \quad(\mathrm{C}=\mathrm{N}): 1610(\mathrm{~s}) ; \quad v(\mathrm{M}-\mathrm{N}): \quad 465(\mathrm{~m}) ; \quad v(\mathrm{M}-\mathrm{O}): 590(\mathrm{w}) ; \quad\left[v_{\mathrm{as}}\left(\mathrm{CO}_{2}\right): 1630(\mathrm{~m})\right.$; $\left.v_{\mathrm{s}}\left(\mathrm{CO}_{2}\right): 1412(\mathrm{~s})\right]^{1} \mathrm{H} \mathrm{NMR}(\delta \mathrm{ppm}): 7.93 \mathrm{~s}(\mathrm{CH}=\mathrm{N}), \quad 6.2-6.7 \mathrm{~m}($ Pyrrole $\mathrm{H}), 3.0-3.5($ Hydrated water), 2.0-3.0(Methyl).TOF-MS(m/z values): $340\left(37 \%, \mathrm{M}^{+}\right), 304\left(10 \%,\left[\mathrm{M}(\mathrm{L})(\mathrm{X})^{]^{+}}\right), 185(46 \%\right.$, $\left.\mathrm{LH}^{++}\right), 146\left(43 \%, \mathrm{C}_{9} \mathrm{H}_{8} \mathrm{NO}^{]^{+}}\right)$;

Manganese(II)- 2-[(1H-pyrrole-2-ylmethylene)amino]phenol complex [Complex IV]

Yellow crystal; Yield: 80\%; Anal. Calcd. for $\mathrm{C}_{11} \mathrm{H}_{15} \mathrm{~N}_{2} \mathrm{O}_{4} \mathrm{MnCl}$ requires (\%): $\mathrm{C}, 40.09 ; \mathrm{H}$, 4.55; N, 8.50; Mn, 16.68. Found: C, 40.07; H, 4.53; N, 8.50, Mn, 16.67 [M.P $\left({ }^{\circ} \mathrm{C}\right): 180$ ]; FTIR( KBr, $\left.\mathrm{cm}^{-1}\right): v(\mathrm{C}=\mathrm{N}): 1618(\mathrm{~s}) ; \mathrm{v}(\mathrm{M}-\mathrm{N}): 501(\mathrm{~m}) ; \mathrm{v}(\mathrm{M}-\mathrm{O}): 598(\mathrm{~m}) ; \mathrm{v}(\mathrm{M}-\mathrm{Cl}): 280(\mathrm{~m})$; TOF-MS(m/z values): $330\left(57 \%, \mathrm{M}^{+}\right), 276\left(21 \%,\left[\mathrm{M}(\mathrm{L})(\mathrm{X})^{]^{+}}\right), 186\left(89 \%, \mathrm{LH}^{\mathrm{j}^{+}}\right), 145(71 \%\right.$, $\left.\mathrm{C}_{9} \mathrm{H}_{8} \mathrm{NO}^{\mathrm{l}}\right) ; \mu_{\mathrm{eff}}(\mathrm{BM}): 5.60$;

\section{Molecular modeling}

3D molecular modeling of the proposed structure of the complexes was performed using HyperChem version 7.1 program package. The correct stereochemistry was assured through the manipulation and modification of the molecular coordinates to obtain reasonable low energy molecular geometries. The potential energy of the molecule was the sum of the following terms $(E)=E_{\text {str }}+E_{\text {ang }}+E_{\text {tor }}+E_{v d w}+E_{\text {oop }}+E_{\text {ele }}$, where all E's represent the energy values corresponding to the given types of interaction $(\mathrm{kcal} / \mathrm{mol})$. The subscripts str, ang, tor, vdw, oop, and ele denote bond stretching, angle bonding, torsion, deformation, vanderwaals interactions, out of plain bending and electronic interaction, respectively. The molecular mechanics describe the application of classical mechanics to determination of molecular equilibrium structures. It enables the calculation of the total static energy of a molecule in terms of deviations from reference unstrained bond lengths, angles and torsions plus non bonded interactions. On account of non-bonded interactions and also the chemical sense of each atom, treat the force field as a set of constants that have to be fixed by appeal to experiment or more rigorous calculations. It has been found that off-diagonal terms are usually largest when neighboring atoms are involved, and so we have to take account of non - bonded interactions, but only between next-nearest neighbors.

\section{Biological activity: Antibacterial screening}

In vitro antibacterial activity of the compounds against Escherichia coli and Staphylococcus aureus were carried out using Muller Hinton Agar media (Hi media). The activity was carried out using paper disc method. Base plates were prepared by pouring $10 \mathrm{ml}$ of autoclaved MullerHinton agar into sterilized Petri dishes $(9 \mathrm{~mm}$ diameter) and allowing them to settle. Molten autoclaved Muller Hinton that had been kept at $48^{\circ} \mathrm{C}$ was incubated with a broth culture of the 
Escherichia coli and Staphylococcus aureus bacteria and then poured over the base plate. The discs were air dried and placed on the top of agar layer. The plates were incubated for $24-30 \mathrm{~h}$ and the inhibition zones ( $\mathrm{mm}$ ) were measured around each disc. As the organism grows, it forms a turbid layer, except in the region where the concentration of antibacterial agent is above the minimum inhibitory concentration and a zone of inhibition is seen. The size of the inhibition zone depends upon the culture medium, incubation conditions, rate of diffusion and the concentration of the antibacterial agent. The solutions of all compounds were prepared in double distilled water and chloramphenicol was used as a reference.

\section{Results and Discussion}

The synthesized compounds are crystalline and non-hygroscopic in nature. These are insoluble in water, partially soluble in ethanol but soluble in acetone, DMF and DMSO. Single crystals of the compounds could not be isolated from any organic solvents; thus no definite structures can be described. However, the analytical and spectroscopic data enables us to predict possible structures. The lattice water molecules have been determined with the help of elemental as well as thermal studies. The biological activities of the complexes were also tested against Escherichia coli and Staphylococcus aureus which were close to the standard drug. Molar conductance values of the complexes and Schiff bases show very low values of molar conductance indicating their non-electrolytic nature[11].The general reaction for the preparation of the metal complexes is

$$
\mathrm{MX}_{2} \cdot \mathrm{YH}_{2} \mathrm{O}+\mathrm{LH} \rightarrow[\mathrm{MLX}] \cdot \mathrm{nH}_{2} \mathrm{O}+\mathrm{HX}+\mathrm{ZH}_{2} \mathrm{O}
$$

Where $\mathrm{M}=\mathrm{Cu}(\mathrm{II}), \mathrm{Co}(\mathrm{II}), \mathrm{Ni}(\mathrm{II}), \mathrm{Mn}(\mathrm{II}), \mathrm{X}=$ Acetate/Nitrate/ Chloride, $\mathrm{Y}=2-6, \mathrm{n}=2-3, \mathrm{Z}$ $=0-4$;

\section{Mass spectra}

This method is particularly useful when a poorly crystalline nature of complexes prevents their x-ray characterization. Mass spectrometry has been successfully used to investigate molecular species in solution ${ }^{12}$. The pattern of mass spectrum gives an impression of the successive fragmentation of the target compound with the series of peaks corresponding to the various fragments. Their intensity gives an idea of stability of fragments. The recorded mass spectra of the ligand and their metal complexes of molecular ion peaks have been used to confirm the proposed formula given in Figure 2a-b The mass spectrum of ligand having a molecular ion peak at $186\{100 \% \mathrm{~m} / \mathrm{z}\}$ and having prominent peak at $145\{34 \% \mathrm{~m} / \mathrm{z}\}$ that corresponds to the $\left[\mathrm{C}_{9} \mathrm{H}_{8} \mathrm{NO}\right]^{+}$, confirming purity of the ligand. The molecular ion peaks of $\mathrm{Cu}(\mathrm{II}), \mathrm{Co}(\mathrm{II}), \mathrm{Ni}(\mathrm{II})$ and $\mathrm{Mn}(\mathrm{II})$ - Ligand complexes were observed respectively at 345,343 , 340 and $330 \mathrm{~m} / \mathrm{z}$ which confirm the stoichiometry of the metal complexes to be $[\mathrm{M}(\mathrm{L})(\mathrm{X})]$ $\mathrm{nH}_{2} \mathrm{O}$. All the synthesized complexes containing metal ion were confirmed by good agreement between the observed and calculated molecular formula ${ }^{13}$. Elemental analysis values are in close agreement with the values calculated from molecular formulas assigned to these complexes, which is further supported by the TOF- mass studies. The molecular ion peak of the complex by the loss of water molecules gave a fragment ion $[\mathrm{M}(\mathrm{L})(\mathrm{X})]^{+}$. All these fragments leading to the formation of the monomeric species $[\mathrm{M}(\mathrm{L})]^{+}$which undergoes demetallation to form the species $[\mathrm{HL}]^{+}$are usually present in the mass spectra of these systems $^{14}$.The last two fragments at $185 / 186$ and $146 / 145$ are $[\mathrm{LH}]^{+}$and $\left[\mathrm{C}_{9} \mathrm{H}_{8} \mathrm{NO}\right]^{+}$of ligand peaks appear in all the complexes shows similar pattern of fragmentation. 
536 BIBHESH K. SINGH et al.

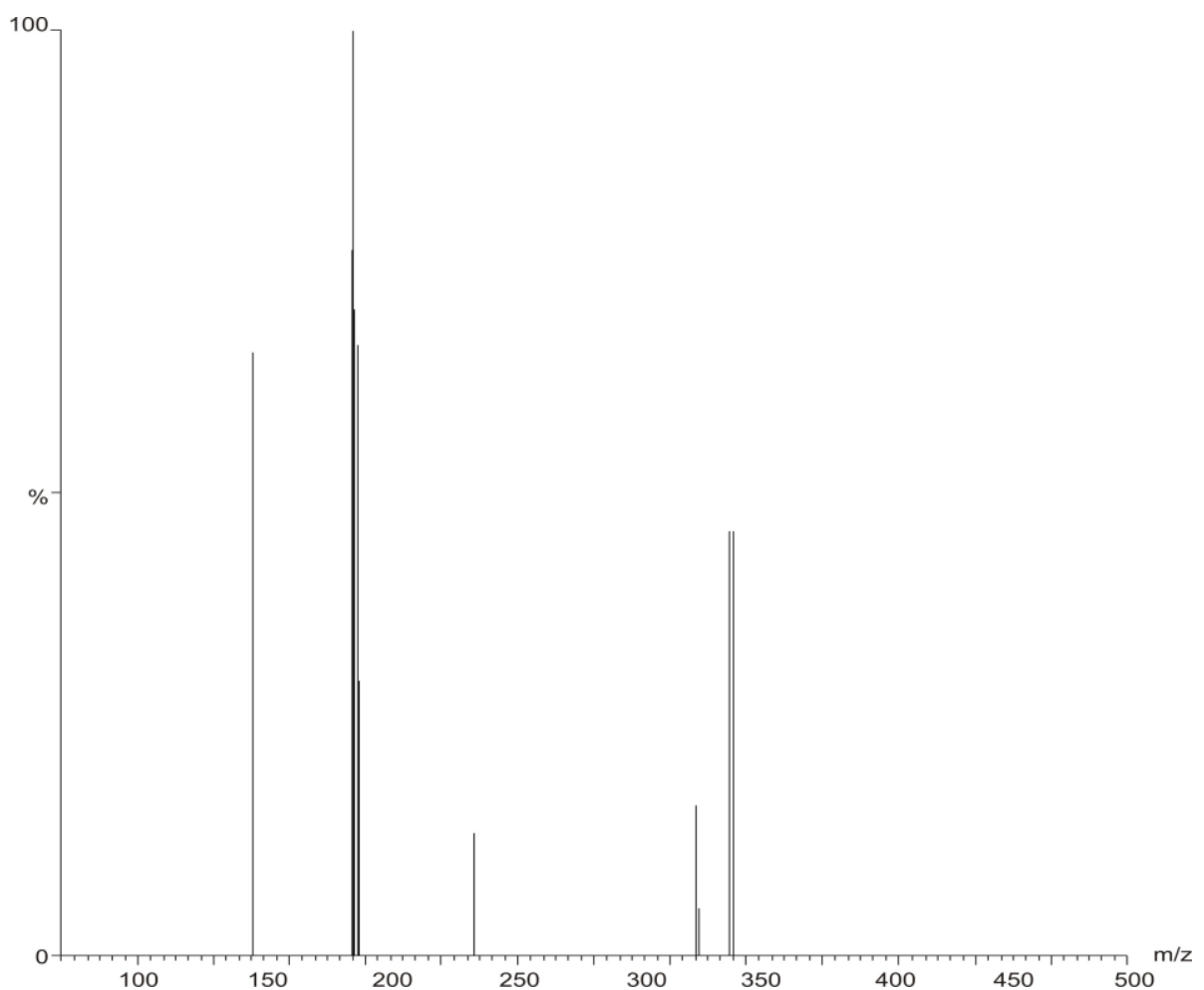

Figure 2a. Mass spectrum of the complex I.

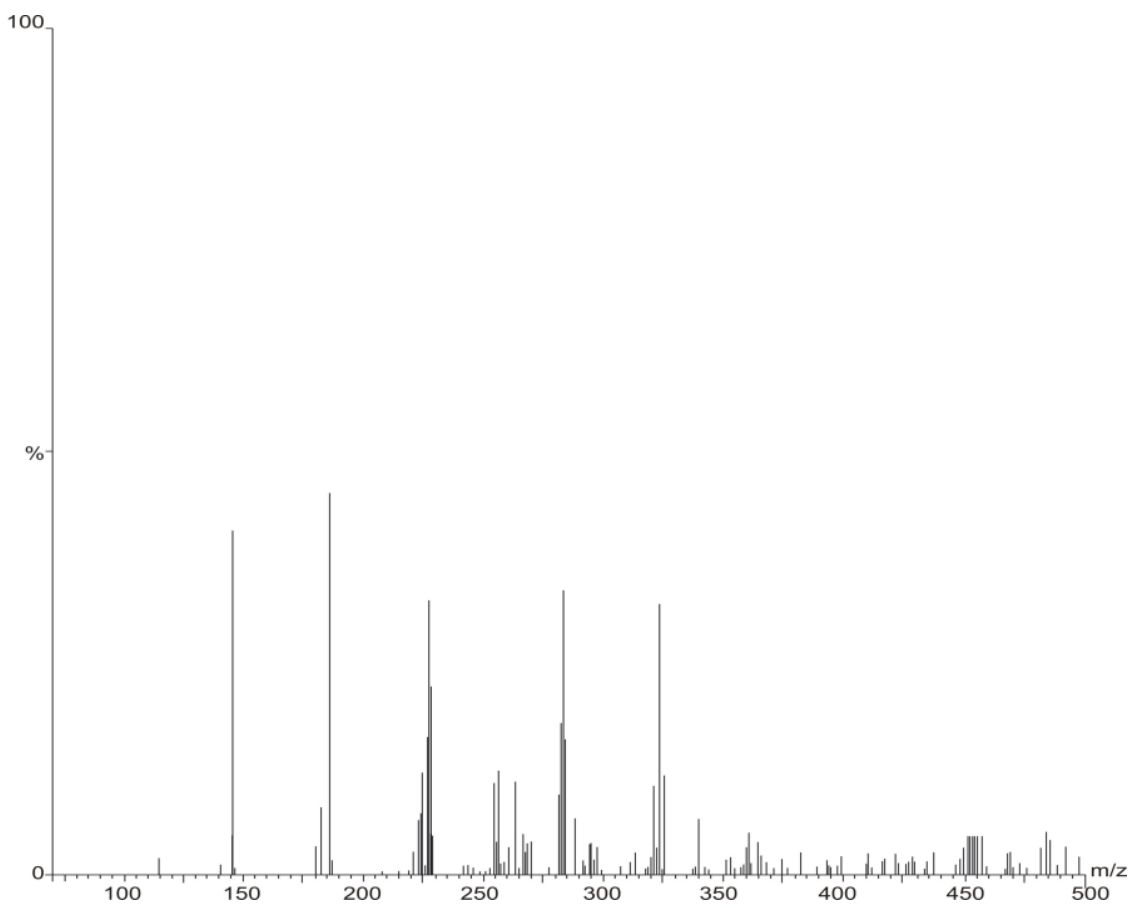

Figure 2b. Mass spectrum of the complex III. 


\section{IR spectra and mode of bonding}

I.r. spectrum of the ligand shows a broad band of medium intensity at $3339 \mathrm{~cm}^{-1}$ due to $v(\mathrm{NH})$ (That may be overlapping with hydrogen bonded O. . H stretching vibrations) ${ }^{15}$. The band due to $\mathrm{N}-\mathrm{H}$ disappeared in the spectra of complexes. The involvement of deprotonated phenolic moiety in complexes is confirmed by the shift of $v(\mathrm{C}-\mathrm{O})$ stretching band observed at $1273 \mathrm{~cm}^{-1}$ in the free ligand to a higher frequency ${ }^{15}$ to the extent $10-20 \mathrm{~cm}^{-1}$. It indicates that nitrogen and phenolic oxygen are directly linked to metal ions ${ }^{15}$. The free Schiff base ligand showed a strong band at $1630 \mathrm{~cm}^{-1}$, which is characteristic of the azomethine $(-\mathrm{HC}=\mathrm{N})$ group ${ }^{16}$. Coordination of the Schiff base to the metal ions through the nitrogen atom is expected to reduce electron density in the azomethine link and lower the $v_{\mathrm{C}=\mathrm{N}}$ absorption frequency due to the $\pi$-back bonding. The band due to $v_{\mathrm{C}=\mathrm{N}}$ is shifted to lower frequencies and appears around $1610-1625 \mathrm{~cm}^{-1}$, indicating coordination of the azomethine nitrogen to metal ions ${ }^{17}$. The weak to medium bands in the two ranges 580-615 and $430-560 \mathrm{~cm}^{-1}$, which could be assigned to the stretching frequencies of the $v(\mathrm{M}-\mathrm{O})$ and $v(\mathrm{M}-\mathrm{N})$ bands, respectively, supporting that the bonding of the ligand to metal ions is achieved by the phenolic oxygen and azomethine nitrogen atom of the ligand ${ }^{18}$. The N-H stretching frequency at $3135-2900 \mathrm{~cm}^{-1}$ in the free ligand (having pyrrole ring) showed considerable shift in all the complexes, indicating participation of this $\mathrm{N}-\mathrm{H}$ group in complexes $^{19}$. The bands in the range of $3352-3575 \mathrm{~cm}^{-1}$ which can be assigned to the stretching frequencies of the $v(\mathrm{OH})$ of water molecules associated to the complexes which are also confirmed by the elemental analyses. In addition to the modified slightly on account of coordination, infrared spectra of the cobalt(II) complex show absorption bands at ca. 1270, $1095,730,1383,965$ and $1035 \mathrm{~cm}^{-1}$ due to terminally bonded monodentate nitrato group ${ }^{20}$. In addition to these two weak bands with a separation of ca. $12 \mathrm{~cm}^{-1}$ appear in the $1800-1700 \mathrm{~cm}^{-1}$ region indicating clearly the exclusive presence of terminal monodentate nitrato group ${ }^{21}$. The $\mathrm{Cu}$ (II) and $\mathrm{Ni}$ (II) complexes have bands in the region $1620-1630(\mathrm{~s}) \mathrm{cm}^{-1}$ and $1412-1418(\mathrm{~s}) \mathrm{cm}^{-1}$ which can be assigned to $v_{\mathrm{as}}\left(\mathrm{CO}_{2}\right)$ and $v_{\mathrm{s}}\left(\mathrm{CO}_{2}\right)$ fundamental stretching bands respectively, which are in agreement with the acetate groups being monodentate ${ }^{18}$.The $\mathrm{Mn}(\mathrm{II})$ complex has $v(\mathrm{Mn}-\mathrm{Cl})$ band at $280 \mathrm{~cm}^{-1}$, confirmed using polyethylene pellets.

\section{${ }^{1} H$ NMR spectra and EPR spectra}

The ${ }^{1} \mathrm{H}$ NMR spectrum of the ligand and its Ni(II) complex have been recorded in DMSO$\mathrm{d}_{6}$ as solvent to confirm the binding of the Schiff base to the metal ions. The spectrum shows the stability of the complex in solution. The tridentate Schiff base ligand possess one phenolic, azomethine and pyrrole group. The ${ }^{1} \mathrm{H}-\mathrm{-nmr}$ spectrum of the ligand showed the aromatic protons as multiplet in the range $6.80-7.70 \mathrm{ppm}$ and peaks in the region $6.2-6.7$ ppm were assigned chemical shift of pyrrole hydrogen ${ }^{22}$. The downfield shifting of the pyrrole hydrogen peak indicating its coordination with $\mathrm{Ni}(\mathrm{II})$ ion. In the spectra of the ligand, the $\mathrm{OH}$ proton of the phenolic ring at $11.76 \mathrm{ppm}$, but the $\mathrm{Ni}(\mathrm{II})$ complex did not shows phenolic proton, indicating deprotonation of the hydroxyl group. The azomethine proton appeared as a sharp singlet at $8.75 \mathrm{ppm}$. Moreover, the azomethine proton of the free ligand is shifted downfield to $7.92 \mathrm{ppm}$, indicating complexation of nitrogen atom of the azomethine with $\mathrm{Ni}(\mathrm{II})$. These observations suggest that the ligand coordinate to the $\mathrm{Ni}$ (II) through the pyrrole nitrogen, phenolic oxygen and nitrogen atom of the azomethine group. In complexes the peak in the region of 3.0-3.5 ppm were assigned for hydrated water and another peak at $4.5 \mathrm{ppm}$ especially in DMSO solvent confirms the hydrogen bonded water molecules $^{22}$. A new peak in the region $\delta 2.0-3.0 \mathrm{ppm}$, characteristic of methyl group are present in the spectrum of the complex are absent in the spectrum of the ligand.

The EPR spectrum of crystalline copper(II) complex samples shows similar features at room temperature and at liquid nitrogen temperature. Basic spectral features at both 
temperatures are same with slightly better resolution at liquid nitrogen temperature. The spectrum of powdered sample of $\mathrm{Cu}$ (II) complex showed normal features with $\mathrm{g}_{\|}>\mathrm{g}_{\perp}>2$ indicating that the unpaired electron lies in the $\mathrm{d}_{\mathrm{x} 2 \mathrm{y}-\mathrm{y} 2}$ orbital ${ }^{23}$, characteristic of square planar geometry around $\mathrm{Cu}(\mathrm{II})$ ion. The exchange interaction parameter term $\mathrm{G}$, estimated from the expression $\mathrm{G}=\left(\mathrm{g}_{\|}-2.0023\right) /\left(\mathrm{g}_{\perp}-2.0023\right)=1.813$, indicating that the ligand has strong field ${ }^{24}$. The value of $G<4$, indicating considerable exchange coupling and the misalignment is appreciable. The value of $A_{\|}(158)$, nuclear hyperfine constant and $\alpha^{2}(0.69)$ degree of covalency support the structure ${ }^{25}$. The $\mu_{\text {eff }}$ value, calculated using the equation $\mu_{\text {eff }}^{2}=3 / 4 \mathrm{~g}^{2}$ av was 1.86 B.M, which closely agreed with the observed magnetic moment.

\section{Electronic spectra and magnetic moment}

The electronic spectra of the complexes were recorded in DMSO. The bands in the 200-380 $\mathrm{nm}$ region coincide with the bands observed in the free ligand. Two relatively less intense bands ( $\mathrm{n} \rightarrow \pi^{*}$ and $\pi \rightarrow \pi^{*}$ ) occur in the $380-450 \mathrm{~nm}$ region, these can be assigned to phenolic oxygen to metal and imine nitrogen to the metal charge transfer transitions, respectively. The electronic spectrum of the Schiff base $\mathrm{Cu}$ (II) complex shows very intense absorption bands in the UV region, attributed to ligand transitions $\left(\mathrm{n} \rightarrow \pi^{*}\right.$ and $\left.\pi \rightarrow \pi^{*}\right)$, and a characteristic broad bands in visible region at $660 \mathrm{~nm}$ and $510 \mathrm{~nm}$ assignable to ${ }^{2} \mathrm{~B}_{1 \mathrm{~g}} \rightarrow{ }^{2} \mathrm{E}_{\mathrm{g}}$ and ${ }^{2} \mathrm{~B}_{1 \mathrm{~g}} \rightarrow{ }^{2} \mathrm{~A}_{1 \mathrm{~g}}$ transitions respectively, indicates the possibility of square planar geometry of metal complex. The $\mathrm{Cu}$ (II) complex has magnetic moment value 1.75B. M. reveals square planar geometry around the metal ion[26]. Cobalt (II) complex shows absorption bands at $665 \mathrm{~nm}$ assigned to ${ }^{4} \mathrm{~A}_{2} \rightarrow{ }^{4} \mathrm{~T}_{1}(\mathrm{P})$ transitions. The existence of spin - orbit coupling also allows some quartet $\rightarrow$ doublet spin transition to occur. Another band at $704 \mathrm{~nm}$ is assigned to ${ }^{4} \mathrm{~A}_{2} \rightarrow{ }^{4} \mathrm{~T}_{1}(\mathrm{~F})$. The expected ${ }^{4} \mathrm{~A}_{2} \rightarrow{ }^{4} \mathrm{~T}_{2}$ transition appearing at a $4500 \mathrm{~cm}^{-1}$ is overlapped by ligand vibration transitions(i.e., the infrared bands) suggests tetrahedral geometry of the complex[26], which is also corroborated by magnetic moment(The magnetic moment of $\mathrm{Co}(\mathrm{II})$ is $4.22 \mathrm{~B}$. M) value of the comple $\mathrm{x}^{26,27}$. The magnetic moments of the paramagnetic complexes have been measured at room temperature $298 \mathrm{~K}$, the $\mathrm{Ni}(\mathrm{II})$ complex has diamagnetic character and shows the square planar geometry around the metal center. Spectra of the nickel complex shows an absorption band at $650 \mathrm{~nm}$, assignable to a ${ }^{1} \mathrm{~A}_{1 \mathrm{~g}} \rightarrow$ ${ }^{1} \mathrm{~A}_{2 \mathrm{~g}}$ transition and a shoulder at $550 \mathrm{~nm}$ corresponding to a ${ }^{1} \mathrm{~A}_{1 \mathrm{~g}} \rightarrow{ }^{1} \mathrm{~B}_{1 \mathrm{~g}}$ transition which are consistent with square planar stereochemistry about the nickel(II) ion. It can be explained with the planar ligand set causes one of the $d$-orbitals $\left(\mathrm{d}_{\mathrm{x} 2^{-} \mathrm{y} 2}\right)$ to be uniquely high in energy and the eight electrons can occupy the other four d-orbitals but leave this strongly antibonding one vacant. The manganese complex show intense absorption at $340 \mathrm{~nm}$ assigned to ligand centered transition while two weak transitions are observed at $375 \mathrm{~nm}$ and $460 \mathrm{~nm}$ may be referred to a combination of MLCT and d-d transition $\left({ }^{4} \mathrm{~A}_{1} \rightarrow{ }^{4} \mathrm{~T}_{1}\right)$, suggesting tetrahedral geometry of the complex. The magnetic moment value of the manganese(II) complex is $5.60 \mathrm{BM}$, may have tetrahedral/ octahedral geometry ${ }^{28}$. The tetrahedral geometry suggested by electronic spectra of manganese(II) complex supported magnetic moment, a high spin tetrahedral complex.

\section{Electrochemistry}

The electrochemical behaviors of the copper(II), cobalt(II) and nickel(II) complexes were studied using cyclic voltametric $(\mathrm{CV})$ technique in DMSO solution containing $0.1 \mathrm{M}$ TBAP. The CVs are presented in Figure 3a-b. The $\mathrm{Cu}(\mathrm{II})$ complex $\left(1 \times 10^{-3} \mathrm{M}\right)$ exhibit a reversible oxidation and reversible reduction peaks at the scan rate $100 \mathrm{mVs}^{-1}$. The copper complex (Figure 3a) showed reversible behavior, with $\Delta \mathrm{E}_{\mathrm{p}}\left(\mathrm{Cu}^{\mathrm{II}}-\mathrm{Cu}^{\mathrm{I}}\right)=-0.21 \mathrm{~V}$ in DMSO solution containing tetra butyl ammonium perchlorate(TBAP) $\left(0.10 \mathrm{~mol} \mathrm{dm}^{-3}\right)$. 


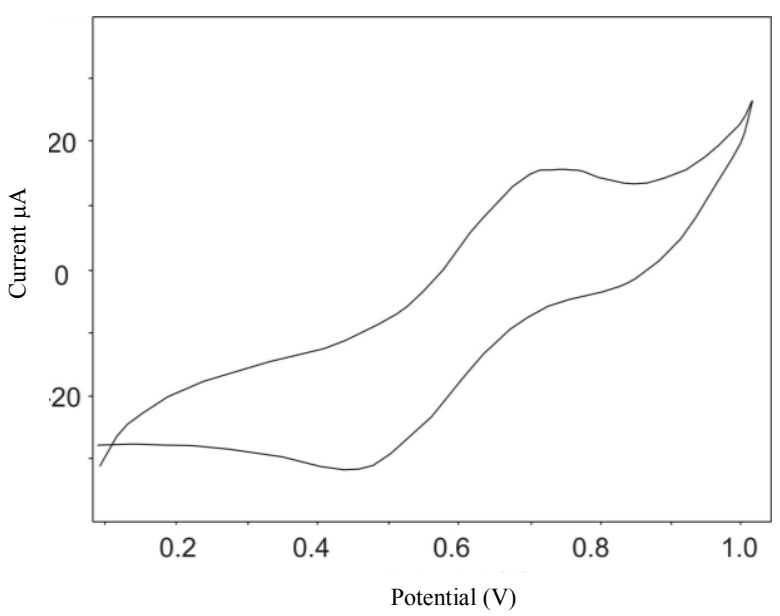

Figure 3a. The cyclic voltamogram of the complex I.

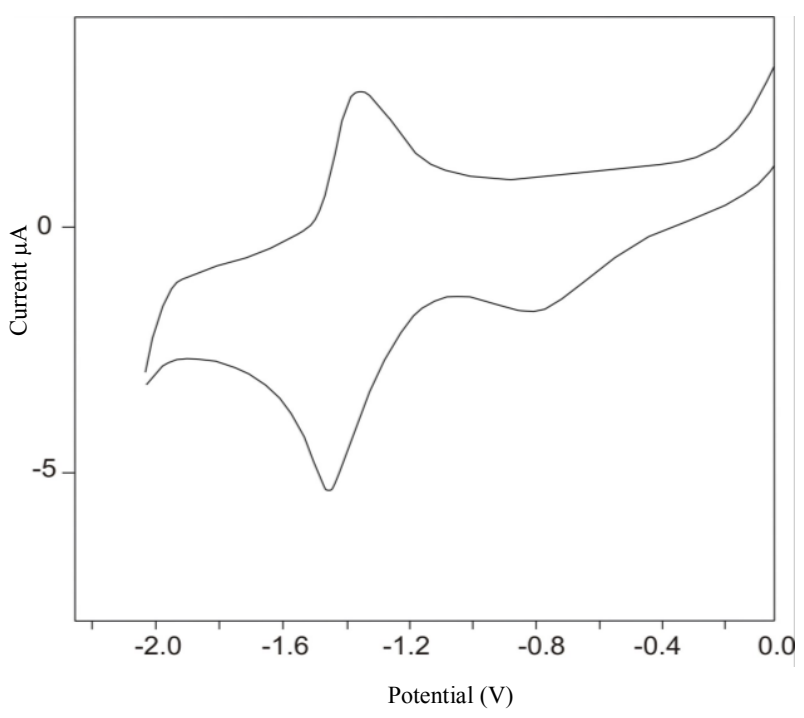

Figure 3b: The cyclic voltamogram of the complex III.

The $\Delta \mathrm{E}_{\mathrm{p}}=-0.21 \mathrm{~V}$ value is consistent with a coordination geometry intermediate between square planar and tetrahedral around the $\mathrm{Cu}(\mathrm{II})$. Besides, unsaturated nitrogen as the donor atom in the ligand stabilizes more a low oxidation state, such as $\mathrm{Cu}(\mathrm{I})$, than a saturated one, by $\pi$ - back bonding between the metal and the nitrogen atom. The other spectroscopic studies confirms square planar geometry around $\mathrm{Cu}(\mathrm{II})$. Cyclic voltamograms of the $\mathrm{Co}$ (II) complex $\left(1 \times 10^{-3} \mathrm{M}\right)$ exhibit reversible oxidation and reduction peaks at 50 and $500 \mathrm{mVs}^{-1}$. At $50 \mathrm{mVs}^{-1}$, the $\mathrm{Co}$ (II) complex shows reversible oxidation peak at $-1.88 \mathrm{~V}$. The peak has been changed to -0.98 for oxidation and $-0.52 \mathrm{~V}$ for reduction processes, respectively. Fig. $3 \mathrm{~b}$ shows the $\mathrm{CV}$ of the nickel complex which exhibited a quasi-reversible one- electron reduction at $100 \mathrm{mVs}^{-1}$ scan rate with a corresponding anodic wave. This reduction is referred to the $\mathrm{Ni}(\mathrm{II}) / \mathrm{Ni}(\mathrm{I})$ couples. The quasi-reversibility of the reduction process are confirmed with the corresponding peak separation value between cathodic peak potential and anodic peak potential $\left(\Delta \mathrm{E}_{\mathrm{p}}=0.121 \mathrm{~V}\right)$ and almost the unity of the ratio of the 
anodic peak current to cathodic peak current. The half wave potential of the nickel complex was located at $\mathrm{E}_{1 / 2}=-1.38 \mathrm{~V}$ verses $\mathrm{Ag} / \mathrm{AgCl}$. Cyclic voltametric experiment on the $\mathrm{Mn}$ (II) complex reveals the presence of an irreversible, anodic process $\left(\mathrm{E}_{\mathrm{p}}=+0.78 \mathrm{~V}\right)$ and quasireversible reduction $\left(\mathrm{E}_{1 / 2}=-1.05 \mathrm{~V}\right)$, which regenerates in the reverse scan of the oxidation of the original complex. The oxidation may be attributed to the $\mathrm{Mn}(\mathrm{II}) / \mathrm{Mn}$ (III) couple, where the $\mathrm{Mn}$ (III) complex after its formation, being quite unstable in the original geometry, evolves to an unidentified differently coordinated species(fragmentation can not be ruled out), which however upon reduction regenerates the Mn(II) complex.

\section{Thermoanalytical studies}

Thermogravimetric (TG) and differential thermogravimetric analyses (DTA) were carried out for metal complexes in ambient conditions. The correlations between the different decomposition steps of the complexes with the corresponding weight losses are discussed in term of the proposed formula of the complexes.

The $\left.[\mathrm{Cu}(\mathrm{L})(\mathrm{X})] \cdot 2 \mathrm{H}_{2} \mathrm{O}\right]$ (complex I) with the general formula $\left[\mathrm{C}_{13} \mathrm{H}_{16} \mathrm{~N}_{2} \mathrm{O}_{5} \mathrm{Cu}\right.$ is thermally decomposed in three successive decomposition steps. The first estimated mass loss $10.45 \%$ (calculated mass loss $=10.47 \%$ ) within the temperature range $315-355 \mathrm{~K}$ may be attributed to the loss of two water molecules. This dehydration range indicates the presence of noncoordinated water molecule in the complex. The DTA curve gives an endothermic peak at $342 \mathrm{~K}$ ( the maximum peak temperature) also confirm this fact. The second step occurs within the temperature range $358-470 \mathrm{~K}$ with the estimated loss of $17.41 \%$ (calculated mass loss $=17.45 \%$ ) may be attributed to the loss of acetate $\left(\mathrm{CH}_{4}+\right.$ $\mathrm{CO}_{2}$ ) gases.The DTA curve gives an endothermic peak at $445 \mathrm{~K}$ ( the maximum peak temperature). The third step occurs within the temperature range $650-725 \mathrm{~K}$ with the estimated loss of $48.90 \%$ (calculated mass loss $=48.95 \%$ ) which corresponds to the loss of organic moiety of the ligand leaving $\mathrm{CuO}$ as residue. The DTA curve gives an exothermic peak at $688 \mathrm{~K}$ ( the maximum peak temperature). The total estimated mass loss $76.76 \%$ (calculated mass loss $=76.87 \%$ ). The end $\operatorname{product}(\mathrm{CuO}$ as residue) was confirmed by comparing observed and calculated mass of pyrolysis product.

The $\left.[\mathrm{Co}(\mathrm{L})(\mathrm{X})] \cdot 2 \mathrm{H}_{2} \mathrm{O}\right]$ (complex II) with the general formula $\left[\mathrm{C}_{11} \mathrm{H}_{13} \mathrm{~N}_{3} \mathrm{O}_{6} \mathrm{Co}\right.$ is thermally decomposed in two successive decomposition steps. The first step occurs within the temperature range $318-355 \mathrm{~K}$ with an estimated mass loss $28.61 \%$ ( calculated mass loss $=28.64 \%$ ) which is resonably accounted for the loss of two water molecules along with $\left(\mathrm{NO}_{2}+1 / 2 \mathrm{O}_{2}\right)$ gases. The DTA curve gives an endothermic peak at $338 \mathrm{~K}$ (the maximum peak temperature). The second decomposition step occurswithin the temperature range $635-718 \mathrm{~K}$ with an estimated loss $49.43 \%$ (calculated mass loss $=49.46 \%$ ), which is reasonably accounted for the loss of organic moiety of the ligand leaving $\mathrm{CoO}$ as residue. The DTA curve gives an exothermic peak at $678 \mathrm{~K}$ ( the maximum peak temperature). The total estimated mass loss is $78.04 \%$ (calculated mass loss $=78.10 \%$ ). The $\mathrm{CoO}$ as end product was confirmed by comparing the estimated/ calculated mass of the pyrolysis product.

The $\left.[\mathrm{Ni}(\mathrm{L})(\mathrm{X})] \cdot 2 \mathrm{H}_{2} \mathrm{O}\right]$ (complex III) with the general formula $\left[\mathrm{C}_{13} \mathrm{H}_{16} \mathrm{~N}_{2} \mathrm{O}_{5} \mathrm{Ni}\right]$ is thermally decomposed in three successive decomposition steps. The first estimated mass loss $10.60 \%$ (calculated mass loss $=10.62 \%$ ) within the temperature range $316-357 \mathrm{~K}$ may be attributed to the loss of two water molecules. The DTA curve gives an endothermic peak at $340 \mathrm{~K}$ ( the maximum peak temperature). The second step occurs within the temperature range $360-474 \mathrm{~K}$ with the estimated loss of $17.65 \%$ (calculated mass loss $=17.70 \%$ ) may be attributed to the loss of acetate $\left(\mathrm{CH}_{4}+\mathrm{CO}_{2}\right)$ gases. The DTA curve gives an endothermic peak at $434 \mathrm{~K}$ (the maximum peak temperature). The third step occurs within the temperature range $655-735 \mathrm{~K}$ with the estimated loss of $49.61 \%$ (calculated mass loss $=$ 
$48.64 \%$ ) which corresponds to the loss of organic moiety of the ligand leaving $\mathrm{NiO}$ as residue. The DTA curve gives an exothermic peak at $676 \mathrm{~K}$ (the maximum peak temperature).

The total estimated mass loss $77.86 \%$ (calculated mass loss $=77.96 \%$ ). The $\mathrm{NiO}$ as end product was confirmed by comparing the estimated/ calculated mass of the pyrolysis product.

The $[\mathrm{Mn}(\mathrm{L})(\mathrm{X})] \cdot 3 \mathrm{H}_{2} \mathrm{O}\left(\right.$ complex IV) with the general formula $\left[\mathrm{C}_{11} \mathrm{H}_{15} \mathrm{~N}_{2} \mathrm{O}_{4} \mathrm{MnCl}\right]$ is thermally decomposed in three successive steps. The first estimated mass loss $10.90 \%$ (calculated mass loss $=10.92 \%$ ) within the temperature range $320-360 \mathrm{~K}$ may be attributed to the loss of three water molecules. The DTA curve gives an endothermic peak at $345 \mathrm{~K}$ (the maximum peak temperature). The second step occurs within the temperature range $363-460 \mathrm{~K}$ with the estimated loss of $11.04 \%$ (calculated mass loss $=11.07 \%$ ) may be attributed to the loss of $\mathrm{HCl}$ gas. The DTA curve gives an endothermic peak at $415 \mathrm{~K}$ ( the maximum peak temperature). The third step occurs within the temperature range $652-740 \mathrm{~K}$ with the estimated loss of $56.44 \%$ (calculated mass loss $=56.49 \%$ ) which corresponds to the loss of organic moiety of the ligand leaving $\mathrm{MnO}$ as residue. The DTA curve gives an exothermic peak at $720 \mathrm{~K}$ (the maximum peak temperature). The total estimated mass loss $78.38 \%$ (calculated mass loss $=78.48 \%$ ). The end product $(\mathrm{MnO}$ as residue $)$ was confirmed by comparing observed and calculated mass of pyrolysis product.

\section{Molecular modeling studies}

Molecular mechanics attempts to reproduce molecular geometries, energies and other features by adjusting bond length, bond angles and torsion angles to equilibrium values that are dependent on the hybridization of an atom and its bonding scheme. In order to obtain estimates of structural details of these complexes, we have optimized the molecular structure of complexes. Energy minimization was repeated several times to find the global minimum. The energy minimization value for tetrahedral and without restricting the structure for the Co(II) complex is almost same i.e, $34.71 \mathrm{kcal} / \mathrm{mol}$. This supports tetrahedral geometry of the Co(II) complex $^{29}$. The optimized molecular structure of the cobalt(II) complex are represented in Figure 4.The figure contains, parrot green color is Co(II), sky blue is carbon, royal/dark blue is nitrogen, blood red is oxygen and white is hydrogen.

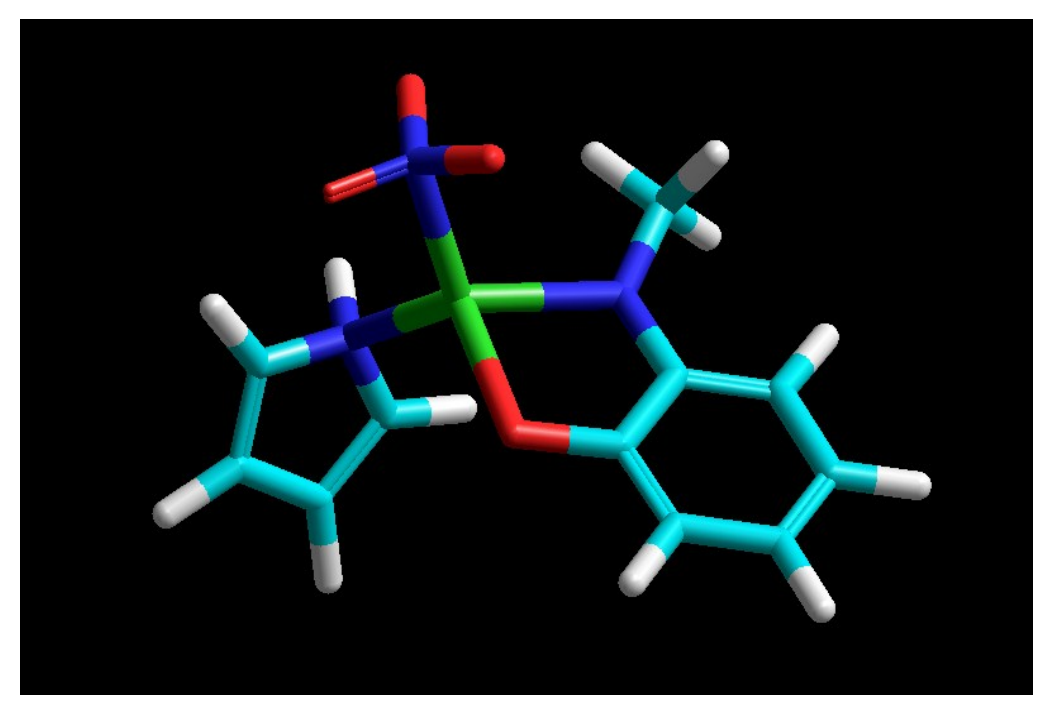

Figure 4. Energy minimized structure of cobalt(II) complex. 


\section{Biological studies}

The bacteriological effect of tridentate Schiff base and its M(II) complexes were determined against two bacteria under different concentration, as described in the experimental section. The agar well - diffusion method was employed for the bacteria with respect to chloramphenicol as standard drug. The results showed that some compounds are very effective on some microorganisms (Figure $5 \mathrm{a}$ b).

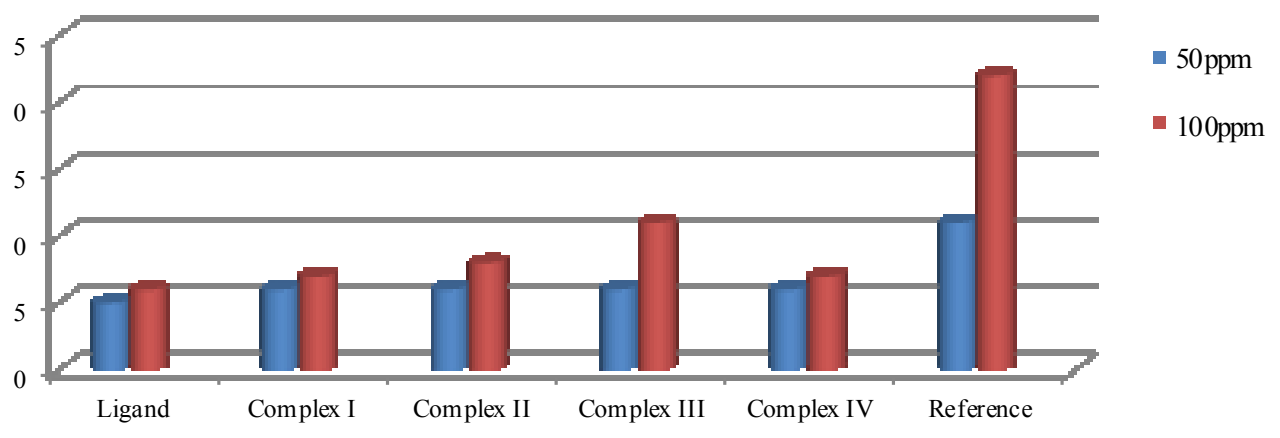

Figure 5a. Effect of different concentration of ligand and complexes with Escherichia coli.

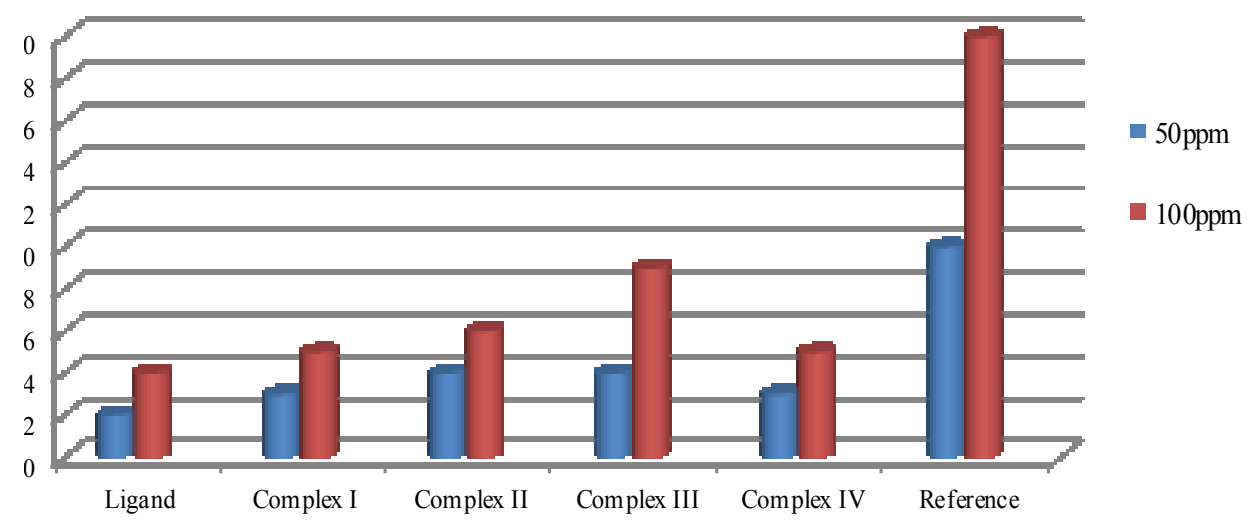

Figure 5b. Effect of different concentration of ligand and complexes with Staphylococcus aureus.

The complex III showed better activity than other metal complexes for both microorganisms. The activity of any compound is a complex combination of steric, electronic and pharmacokinetic factors. A possible explanation for the toxicity of the complexes has been postulated in the light of chelation theory. It was suggested that the chelation considerably reduces the charge of the metal ion mainly because of partial sharing of its positive charge with the donor groups and possible $\pi$ - electron delocalization over the whole chelate ring. This increases the lipophilic character of the metal chelate which favors its permeation through lipoid layers of cell membranes. Furthermore, the mode of action of the compounds may involve the formation of a hydrogen bond through $-\mathrm{N}=\mathrm{C}$ group of the chelate or the ligand with the active centers of the cell constituents resulting in interference with the normal cell process. The higher bacteriotoxicity experienced by the compounds 
may be ascribed to the fact that the metal ions are more susceptible towards the bacterial cells than ligands ${ }^{30}$.

\section{Conclusion}

With the help of various physico-chemical techniques, geometries of the newly synthesized compounds have been proposed (Figure 6). Metal complexes were found to be monomer and involved coordination through nitrogen and oxygen atoms of the ligand giving tetrahedral/ square planar geometry. The ligand is so flexible to satisfy tetrahedral/ square planar geometry has been confirmed with the help of different studies. The Ni(II) complexes were found to be most active against Escherichia coli and Staphylococcus aureus bacteria.

\section{Acknowledgment}

The authors are thankfully acknowledge to council of scientific and industrial research (CSIR), University Grants Commission(UGC), New Delhi, India for financial support.

\section{References}

1 (a) McCleverty J A and Meyer T J, Comprehensive Coordination Chemistry II, From Biology to Nanotechnology, Elsevier, Amsterdam, 2004, 1, 411; (b) Boghaei D M and Mohebi S, Tetrahedron, 2002, 58, 5357.

2 (a) Vashi K and Naik H B, Eur J Chem., 2004, 1, 272; (b) Bhendkar A K, Vijay K and Raut A W, Acta Ciencia Indica Chem., 2004, 30 29. (c) Hossain M E, Allam M N, Begum J, Akbar M A, Uddin M N, Smith F and Hynes R C, Inorg Chim Acta, 1996, 249, 207.

3 Kuzmin V E, Artemenko A G, Lozytska R N, Fedtchouk A S, Lozitsky V P, Muratov E N and Mescheriakov A K, Environ Res., 2005, 16,219.

4 Supuran C T, Barboiu M, Luca C, Pop E, Brewster M E and Dinculescu A, Eur J Med., 1996, 31, 597.

5 (a) Negm N A and Zaki M F, Colloids Surf B: Biointerfaces, 2008, 64, 179;

(b) Deniel V P, Murukan B, Kumari B S and Mohanan K, Spectrochim Acta A, 2008, $70,403$.

6 (a) Ray A, Banerjee S, Butcher R J, Desplanches C and Mitra S, Polyhedron, 2008, 27, 2409; (b) Mohamed G G, Omar M M and Hindy A M M, Spectro Chim Acta A, 2005, 62, 1140 .

7 Berube C D, Gambarotta S, Yap G P A and Cozzi P G, Organometallics, 2003, 22, 434.

8 Banjo A D, Lawal O A and Adeyemi A I, World Appl Sci., 2006, 1(1), 29.

9 Menichetti F, Cli Microbial Infect, 2005, 11(3), 22.

10 Singh B K, Prakash A, Rajour H K, Bhojak N and Adhikari D, Spectrochim Acta A, 2010, 76, 376.

11 Vale R L, Borges M M, Sandro LEE De and Gilmarra G E, Inverse Problems in Science Engineering, 2006, 14, 511.

12 (a) Sanmartin J, Novio F, Garcia-Deibe A M, Fondo M, Ocampo N and Bermejo M R, Polyhedron, 2006, 25, 1714; (b) Beloso I, Castro J, Garcia-Vazquez J A, PerezLourido P, Romero J and Sousa A, Polyhedron, 2003, 22, 1099; (c) Singh B K, Prakash A and Adhikari D, Spectrochim Acta A, 2009, 74, 657.

13 Swamy S J and Pola S, Spectrochim Acta A, 2008, 70, 929.

14 Yoshida N, Ichikawa K and Shiro M J, Chem Soc Parkin Trans., 2000, 2, 17.

15 (a) Kannappan R, Tanase S, Mutikainen I, Tureinen U and Reedjik J, Polyhedron, 2006, 25, 1646. (b) Badwaik V B, Deshmukh R D and Aswar A S, J Coord Chem., 
2009, 62(12), 2037; (c) AbouEl-Enein S A, El-Saied F A, Kasher T I and El-Wardany A H, Spectrochim Acta A, 2007, 67, 737.

16 Ramesh R and Maheshwaram S, J Inorg Biochem., 2003, 96, 457.

17 Ali S A, Soliman A A, Aboaly M M and Ramadan R M, J Coord Chem., 2002, 55, 1161.

18 Nakamoto K, Infrared and Raman Spectra of Inorganic and Coordination Compounds, $5^{\text {th }}$ Edn., Wiley-Interscience, New York, 1997.

19 Chandra S and Kumar U, Spectrochim Acta A, 2004, 60, 2825.

20 (a) Addison C C and Sultons D, Prog Inorg Chem., 1967, 8, 195; (b) Addision C C, Logan N, Wallwork S C and Garner C D, Quart Rev Chem Soc , 1971, 25, 289.

21 (a) Lever A B P, Manto Vani E and Ramaswami B S, Can J Chem., 1971, 49, 1957.(b) Choca M, Ferraro J R and Nakamoto K, J Chem Soc A,1972, 2297.

22 Silverstein R M and Webster F X, Spectrometric Identification of Organic Compounds $6^{\text {th }}$ Edn., Wiley-India, 2007.

23 Bew M J, Hathaway B J and Faraday R R, J Chem Soc Dalton Trans., 1972, 1229.

24 Hathaway B J and Billing D E, J Coord Chem Rev., 1970, 5, 143.

25 Manimekalai A and Shivkumar B S, Ind J Chem A, 2004, 43, 2568.

26 Nakamoto K and McCarthy S J, Spectroscopy \& Structure of Metal Chelate Compounds, John Wiley \& Sons, USA, 1968.

27 Ciampolini M, Struct Bonding., 1969, 6, 52.

28 (a) Lever A B P, Inorganic Electronic Spectroscopy, Elsevier, Amsterdam, 1968, (b) Figgis F N, Introduction to Ligand Fields, Wiley, New York, 1963.

29 Singh B K, Sharma R K and Garg B S, Spectrochim Acta A, 2006, 63, 96.

30 Phaniband M A and Dhumwad S D, Trans Met Chem, 2007, 32, 1117. 


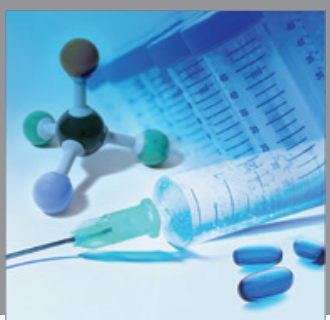

International Journal of

Medicinal Chemistry

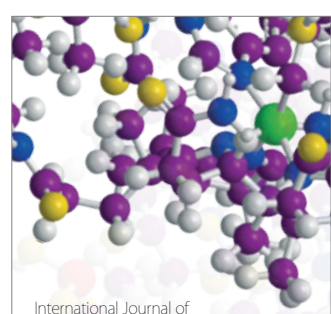

Carbohydrate Chemistry

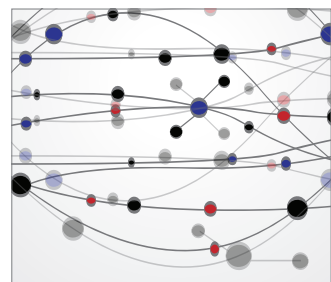

The Scientific World Journal
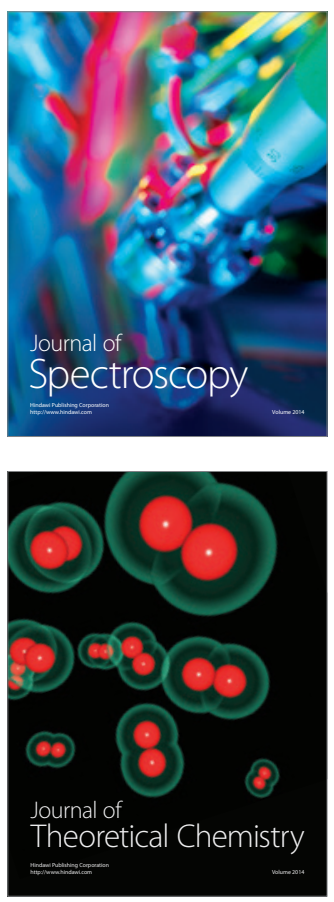
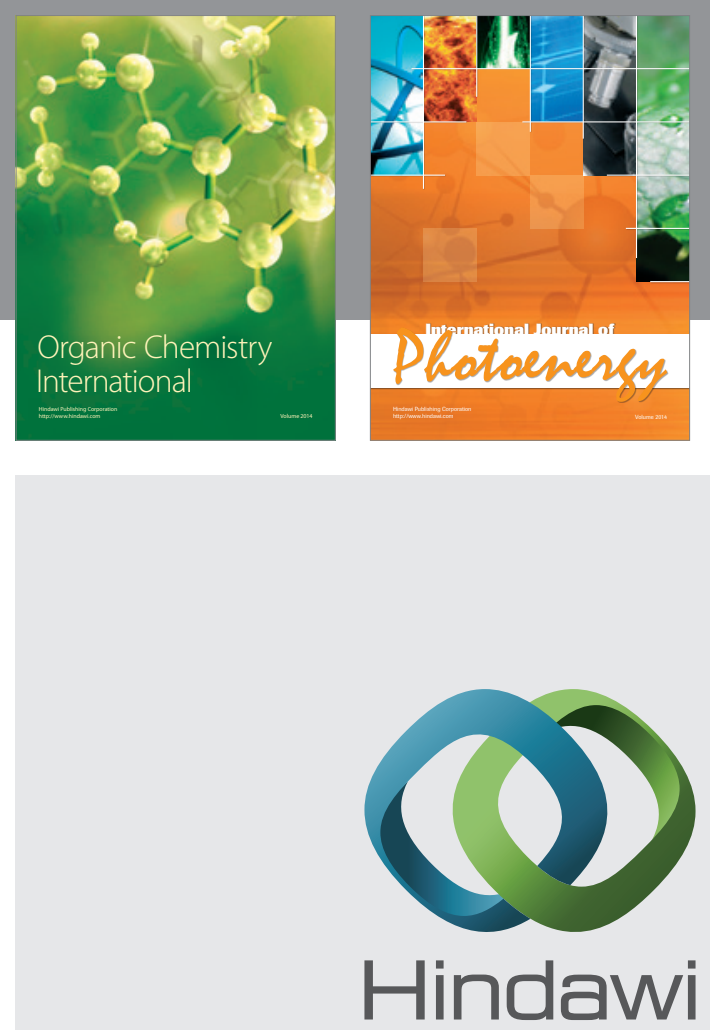

Submit your manuscripts at

http://www.hindawi.com
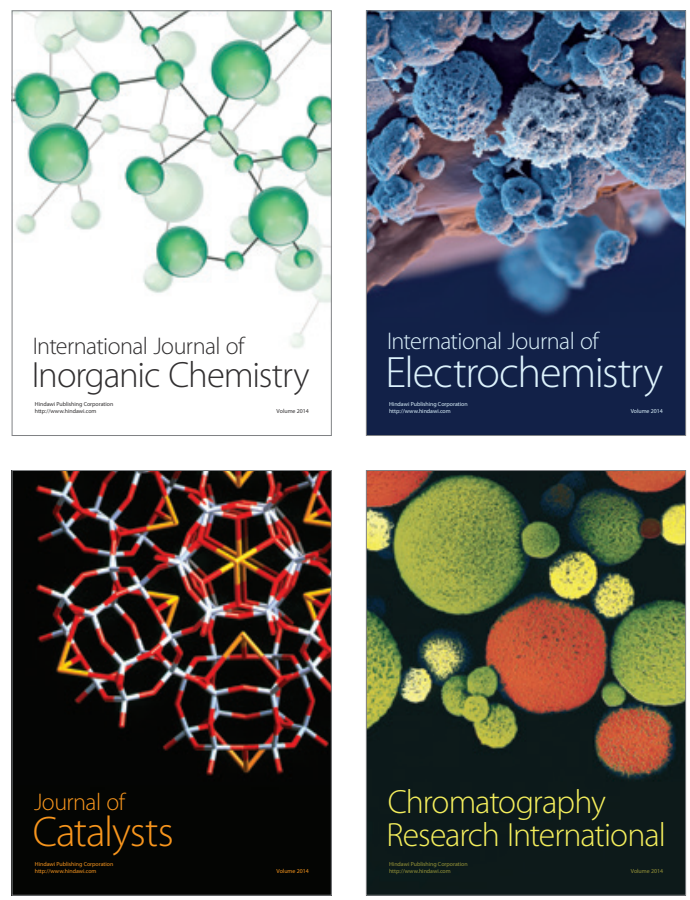
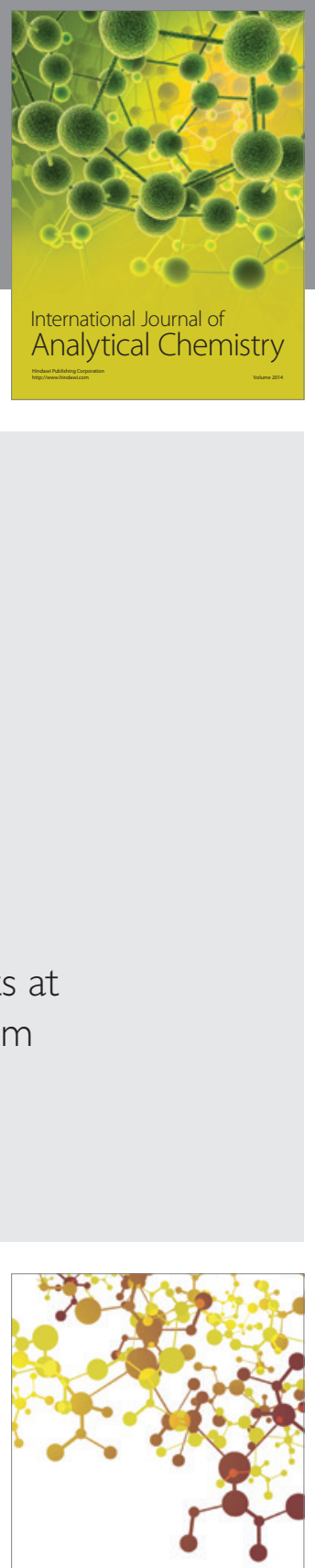

Journal of

Applied Chemistry
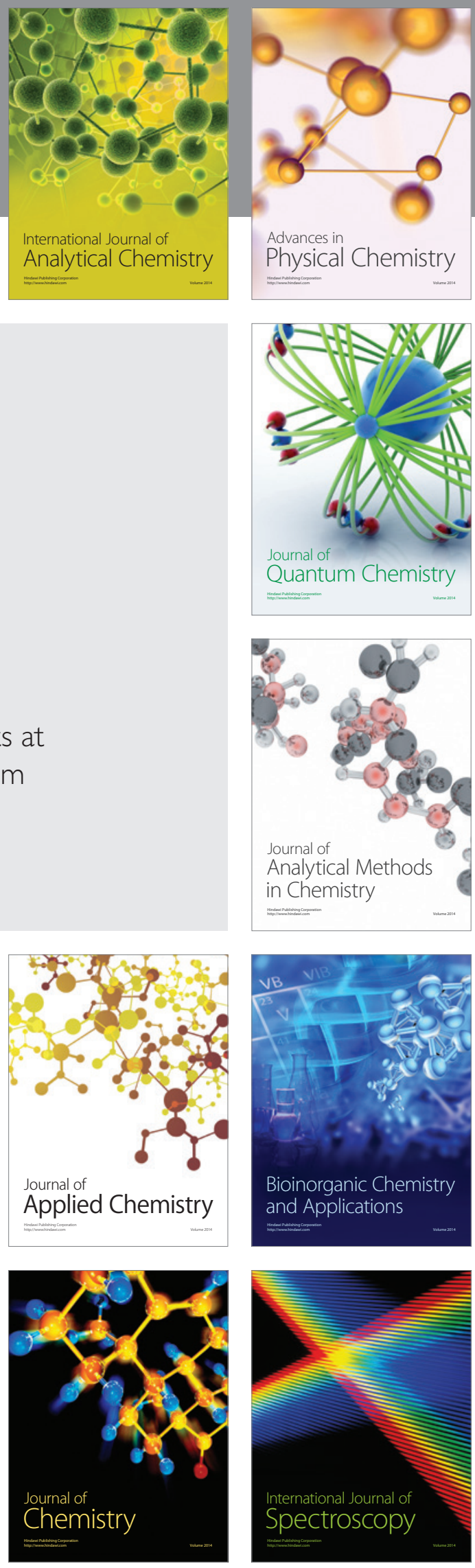